\title{
Structure, use, and syntactic ecology in language obsolescence
}

\author{
DAVID ADGER \\ Queen Mary University of London \\ Email: d.j.adger@qmul.ac.uk
}

\begin{abstract}
Nancy Dorian's foundational work on the loss of Gaelic in the East Sutherland communities continues to provide important insights into the nature of the process of language change in situations of obsolescence. In this article I look at a subset of Dorian's data from the perspective of current syntactic theory, and argue that the connected loss of such apparently different constructions as objects of non-finite verbs, inalienable possessive structures, and a range of passives, and the concomitant restructuring of the grammar, all follow from the interaction between a reduction in agreement features on a functional head and the broad syntactic ecology of the language. This approach makes sense of why these apparently disparate constructions all undergo the particular kinds of change that are seen, changes which are mysterious from the perspective that an obsolescing language should alter to become more like the dominant language (in this case English) which is replacing it.
\end{abstract}

Keywords: Agreement, Language Obsolescence, Scottish Gaelic, syntax, sociolinguistics

\section{Résumé}

Mots-clés : keyword 1, keyword 2, keyword 3

\section{INTRODUCTION}

In situations where languages are obsolescing, the grammar of the younger speakers can restructure in quite radical ways. Some of the most interesting data casting light on this process comes from Nancy Dorian's work on the Scottish Gaelic speaking communities of East Sutherland in the 1960s and since. East Sutherland at this time was a sociolinguistically interesting situation in the Gaelic context because it was quite dramatically isolated from the more numerous Gaelic speaking communities of the Western Isles and the Western Highlands of Scotland, and because the speakers that Dorian worked with were not literate in Gaelic, so there was little normative pressure on the language as it changed.

A version of this was presented at the Queen Mary Linguistics Department's Linglunch on 7th October 2015. Many thanks to all the participants for their comments and questions. Especial thanks to Devyani Sharma for very speedy comments on a rather drafty draft. Many thanks also to the audience of NWAV 44 at the University of Toronto for comments and feedback, to two anonymous reviewers for the Canadian Journal of Linguistics, and to the editors of this issue. 


$$
\text { “adger cjl” — 2016/11/28 - 11:36 - page } 2 \text { - \#2 }
$$

This paper argues that some of the changes that Dorian reports come from the interaction of a loss of agreement features with two general factors. The first of these is a general principle of structure: agreement features are required to license a certain kind of null prononimal, so loss of these features leads to the inability to license this pronominal. The second factor is related to use, rather than structure. In circumstances where variants are in a hyponymic rather than synonymic relationship, the variant with a more narrow distribution can be lost with no loss of expressive power. These two general factors, however, operate within the linguistic system of the language. The way that the constraints of syntax are specified for a particular language affects the types of surface patterns that change, in much the same way that the ecology of a geographical area shapes patterns of population change and speciation. Structures that involve loss of a feature become subject to pre-existing but different constraints in the language. These pre-existing contraints form a kind of syntactic ecology for the change. This approach (loss of features, general principles of structure and use, and the prevailing syntactic ecology of the particular language) explain why certain changes take place (and not others) and why the changes move in the direction that they do. We will see that the direction of change is not well explained by appeal to surface properties of the dominant language (English), or by surface oriented analogy.

The main conclusion, then, is that the patterns of variation and change we see in the East Sutherland case are best explained by abstract systemic reorganization of the syntax, rather than by convergence to other languages, or by analogical processes.

\section{Changes in East Sutherland Gaelic}

Dorian (1973) and Dorian (1978) outlines some major changes in the syntax of East Sutherland Gaelic. These changes involve possessive constructions, as well as two different kinds of passive.

Focussing first on nominal possessives, Gaelic across Scotland has two grammatical strategies for these. One strategy involves realizing the possessor as a postnominal genitive, or, when it is pronominal, a prenominal proclitic. ${ }^{1}$

(1) $\quad$ bràthair Sheumais
brother Seumas.GEN
'Seumas' brother.'
b. a bhràthair
his brother
'His brother'

\footnotetext{
${ }^{1}$ Examples annotated ESG are from Dorian's work. Unannotated examples are from my own fieldwork on Western Isles varieties of Gaelic. There is no evidence for relevant variation in these constructions in those varieties, so such examples can be taken as broadly representative of Western Gaelic dialects. Dorian uses IPA for ESC; I have regularized this to standard Gaelic spelling for easy comparison with the Western varieties' structures.
} 

c. mo bhràthair
my brother
'My brother'

The other involves a prepositional structure appearing after a definite nominal.
a. am peann aig Seumas
the pen at Seumas
'Seumas's pen'
b. am peann aige
the pen at. $3 \mathrm{~S}$
'His pen'
c. am peann agam
the pen at. $1 \mathrm{SG}$
'My pen'

Prepositions in Gaelic inflect for agreement features when their object is a pronoun, in which case the inflection takes the place of the pronoun, as can be seen in (2-b-c).

At the time that Dorian undertook her fieldwork, the oldest speakers, fluent in ESG, restricted their use of the proclitic form to a narrow range of contexts involving inalienable possession ${ }^{2}$. Over the course of her fieldwork, she reports that the younger generations of speakers use the proclitic forms less and less. In the oldest ESG speakers, the full paradigm of proclitic possesive forms is only obtainable with some effort. Speakers find it possible, though not natural, to access pronominal clitic forms to express the relevant possessive meanings. Aside from some fairly fixed expressions involving kinship and bodyparts, the singular possessives typically, and the plural possessives invariably are replaced by the prepositional possessives. This change involves a reduction in the range of variants used to express possession.

The second area where Dorian reports change is in passive constructions. There are two kinds of passives in ESG. The first involves using the suppletive verb $\mathrm{dol}$, 'go' as follows:

(3) Chaidh na daoine a bhathadh anns an loch go.PAST the men PRT drown.VN in the loch 'They were drowned in the loch.' drown.VN

(4) Chaidh am bathadh pro anns an loch go.PAST PRT.3PL drown.VN in the loch 'They were drowned in the loch.'

\footnotetext{
${ }^{2}$ I will leave the genitive aside here. There is an argument to be made that a loss in genitive case marking is also tied to a loss in agreement features, but that is more tendentious than the argument I will make for the pronominal forms, and Dorian provides less information about the syntax of genitives in ESG, so it is harder to evaluate. There is a general loss of genitive across varieties of Gaelic, suggesting that change may have a different cause to the changes discussed here.
} 


$$
\text { “adger cjl" — 2016/11/28 - 11:36 — page } 4 \text { — \#4 }
$$

In these 'go'-passives, the object of the verb (which is in a non-finite form) appears before it, with a particle $a$, homophonous with the third singular masculine possessive pronoun procliticized to the verb. When the object is pronominal, this particle is replaced by a particle that marks the relevant person number and gender properties, and is homophonous with the possessive proclitics just mentioned.

Dorian reports that as we look down the age range, however, new forms emerge for when the object is pronominal (see section 4 for details). The first new form involves a full pronoun in its non-possessive form. Dorian reports some variation in whether the particle after the pronoun appears in a form that shares number and gender features.

(5) Chaidh iad a bhathadh anns an loch go.PAST they PRT drown.VN in the loch 'They drowned in the loch.'

(6) Chaidh iad am bathadh anns an loch go.PAST they PRT.3PL drown.VN in the loch 'They drowned in the loch.'

Here we see a syntactic change from the use of a possessive proclitic to a full pronoun.

There is another passive construction that is also undergoing change during this period. In this construction, the promoted object appears as the subject of the auxiliary verb bith, 'be' which is followed by a particle marking aspect (Dorian presents data with the perfect aspect). In the oldest speakers, these 'be'-passives involve an aspectual particle followed by the verb, with a possessive proclitic, which I will gloss as PRT with relevant agreement features, which shares features with the subject.

$$
\begin{aligned}
& \text { a. Bha iad air an cumail } \\
& \text { be.PAST they PERF PRT.3PL keep.VN } \\
& \text { 'They were kept.' } \\
& \text { b. Bha i air a cumail } \\
& \text { be.PAST she PERF PRT.3SF keep.VN } \\
& \text { 'She was kept.' } \\
& \text { c. Bha e air a chumail } \\
& \text { be.PAST they PERF PRT.3SM keep.VN } \\
& \text { 'It was kept.' }
\end{aligned}
$$

However, Dorian reports an age effect of this phenomenon (section 4 gives Dorian's quantitative data). Younger speakers have a variant where no agreement takes place, and we find the same proclitic with all forms:

(8) Bha iad/i/e air a chumail

be.PAST they/she/he PERF PRT.3SM keep.VN

'They, she, him were/was kept'

There is a further change that takes place in the Gaelic of the youngest speakers, where the two passive constructions end up in variation. The Subject-Aspectual 


$$
\text { “adger cjl" — 2016/11/28 - 11:36 - page 5 — \#5 }
$$

structure that usually appears with bith, 'be', can, for some speakers, appear with dol, 'go', so we have the emergence of a new point of variation between (9) and (10) for these speakers:

(9) Chaidh iad air a bhathadh anns an loch go.PAST they PERF PRT drown.VN in the loch 'They drowned in the loch.'

(10) Tha iad air a bhathadh anns an loch be.PRES they PERF PRT drown.VN in the loch 'They drowned in the loch.'

There is one final relevant datum from ESG. In Western varieties of Gaelic, the object of a non-finite verbal form is realised by proclitics homophonous with the possessve proclitics. For simple aspect, the only way to express simple present tense in Gaelic, the aspectual particle merges with the proclitic into a set of fused forms, as in (12):

$$
\begin{aligned}
& \text { a. An robh a' ghrian gan dalladh? } \\
& \text { Q PST be.PAST the sun SIMP.3PL blind.VN } \\
& \text { 'Was the sun blinding them.?' } \\
& \text { b. An robh a' ghrian gad dalladh? } \\
& \text { Q PST be.PAST the sun SIMP.2SG blind.VN } \\
& \text { 'Was the sun blinding you?' }
\end{aligned}
$$

However Dorian (1978) reports that such structures barely exist in ESG (she records one single example). Rather than (11), all ESG speakers, even the most fluent, have the following type of structure, ungrammatical in Western varieties:

$$
\begin{aligned}
& \text { An do robh a' ghrian dalladh iad } \\
& Q \text { PST be.PAST the sun blind.vN them } \\
& \text { 'Was the sun blinding them?' }
\end{aligned}
$$

ESG

There is no variation in this construction within ESG, but there is a major syntactic difference between ESG here and other varieties of Gaelic. I will argue that this dialectal difference is part and parcel of the other changes that the language was going through at the time.

What I want to do in this paper is to present an argument that a syntactic analysis of these constructions allows us to understand why these changes progressed the way that they did. I'll propose that there is a unifying factor here, which is a narrowing in the richness and range of the agreement features that license a null pronominal pro. If a speaker's grammar does not allow them access to the relevant agreement features, pro cannot be licensed, and the language restructures to remain consistent with general syntactic principles that constrain the licensing of null pronouns. I'll argue that these four cases of change (assuming that ESG has innovated from a common Gaelic system for objects of non-finite verbs) all have the same underlying reason, but that 


$$
\text { "adger cjl" — 2016/11/28 - 11:36 — page } 6 \text { - \#6 }
$$

the particular solutions that the language comes up with to maintain a syntactic system depend on what other resources are available in the speakers' grammars for the particular constructions, the language's syntactic ecology.

\section{Possessives}

\subsection{Possessive structures}

The two possessive strategies mentioned above for ESG are found across Gaelic varieties. Adger (2013) suggests a way of structurally unifying the two possessive strategies in Gaelic. The structure proposed there for mo bhràthair, 'my brother' looks roughly as follows (I have abstracted away from details of the theoretical implementation not relevant here):

(13)

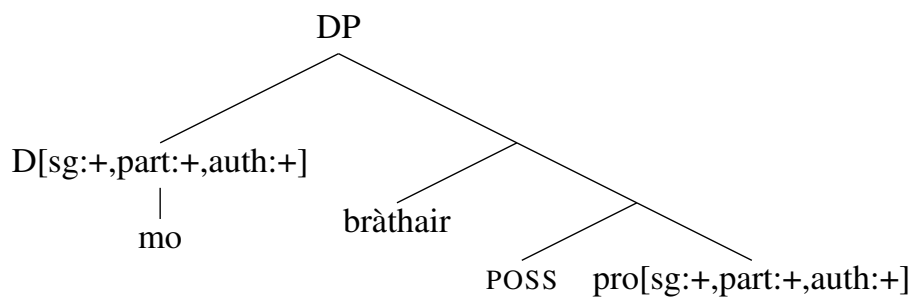

The first aspect of the proposal to note is that the possessive proclitic mo is treated as a determiner. Evidence for this is that it is in complementary distribution with definite determiners (it also functions like a determiner in other ways-see Adger 2013 for further details).

$$
\begin{aligned}
& \text { a. a mhac } \\
& \text { his son } \\
& \text { 'his son' } \\
& \text { b. *an a mhac } \\
& \text { the his son } \\
& \text { 'his son' }
\end{aligned}
$$

There is good evidence that the proclitic structure involves a null pronominal after the noun as shown in (13). Hale and McCloskey (1984) provide a battery of arguments for a similar structure in Modern Irish, but I will replicate just one here for Scottish Gaelic. Gaelic has a series of emphatic particles that attach to pronouns:
a. Tha mi toilichte
be.PRES I happy
'I am happy'
b. Tha mise toilichte
be.PRES I-EMPH happy
'I am happy' 
The generalization about these elements is that they attach to pronouns. Whenever we see a pronoun, we can attach an emphatic particle to emphasize the pronoun. We can see this when pronouns are in subject position, as above, as well as in object position, or in a clefted position:
a. Bhuail Iain thusa
hit.PAST Iain you-EMPH
'Ian hit YOU.'
b. Is e esan a bhuail mi
COP it he-EMPH that hit I
'It's HIM that I hit.'

Recall that prepositions inflect for agreement. If the pronoun is either a null pronoun, or it is somehow morphologically melded with the preposition, then we would expect that the emphatic elements should attach to the preposition. This is correct:

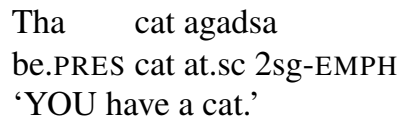

Turning to the proclitic possessives, if these were pronouns, we would expect to find the emphatic particle following them, but this is resolutely ungrammatical:
(18) *Tha mo-se bhràthair tinn be.PRES my-EMPH brother happy 'MY brother is happy.'

Instead we find the emphatic element attached to the noun.

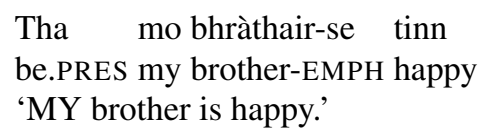

Assuming then, that emphatic particles always attach to pronouns, (19) motivates the idea that there is a null pronoun after the noun and the structure sketched above in (13).

In (13), I have specified the pro with a set of features marking person, number and gender. pro is the element that directly specifies a semantic referent, and so it bears a number of semantically relevant features. However, being null, it obviously cannot express those features morphologically. That job is taken over by $\mathrm{D}$, which bears a set of features that agree with those on pro, just as in familiar pro-drop languages like Italian (Rizzi 1982).

I assume person, number and gender to be encoded by binary features following Noyer's (1992) typological investigation of agreement systems: [part: \pm ] (distinguishing speech act participants (first and second person) from non-participants (third person), [auth: \pm ] (author-distinguishing first from second), and [fem: \pm ] (distinguishing feminine and masculine). In Gaelic, [auth] is only relevant when [part] 


$$
\text { “adger cjl” - 2016/11/28 - 11:36 - page } 8 \text { - \#8 }
$$

has a + value, and [fem] is only relevant when [part] has a - value. This motivates two versions of $\mathrm{D}$, as follows:

$$
\begin{array}{ll}
\text { a. } & \text { D[part:+, sing: } \pm \text {, auth: } \pm] \\
\text { b. D[part:-, sing: } \pm \text {, fem: } \pm]
\end{array}
$$

These D's are entered into the syntactic construction of the noun phrase, agree with the semantically active features on pro, and the agreement operation values the features, so they can be realised in the appropriate morphological form.

The fundamental syntactic condition on pro is that it enters into an agreement relation with some element that can identify it. Under the analysis proposed here, D bearing unvalued agreement features plays that role, so Gaelic is analysed as prodrop in these possesive constructions.

The final aspect of the structure in (13) is the element Poss. I will follow Adger (2013)'s analysis for Gaelic possessives, simplifying the proposal for my purposes here. In Adger's proposal, possessive semantics is introduced by a relational functional category, which I notate here as POSS and which takes the possessor as one argument and the possessee as another. Where the possessive relationship is one of kinship, as in mo bhràthair, 'my brother', the relevant lexical item looks as follows:

$$
\emptyset:: \operatorname{POSS}:: \lambda \times \lambda \mathrm{y} \cdot \operatorname{KIN}(\mathrm{x}, \mathrm{y})
$$

Here the phonological realization is zero $(\emptyset$ before ::), its syntactic category is POSs, and its semantics is the lambda-term to the right (following ::).

Syntactically, and semantically, POSS combines with the possessee and returns a semantic function that combines with the possessor to give a meaning where the possessee is kin to the possessor. The function of the $\mathrm{D}$ (mo in mo bhràthair) is syntactically to license the presence of a null pronominal, and semantically to act as a definite determiner.

Speakers across dialects in the Western Isles have a preference for the genitive/proclitic structure for uniquely and inalienably possessed elements, such as bodyparts and kinship terms.
a. cridhe Sheumais
heart Seumas.geN
'Seumas' heart'
b. *an cridhe aig Seumas the heart at Seumas
'Seumas' heart
c. corrag Sheumais
finger Seumas.GEN
'Seumas' finger'
d. a' chorrag aig Seumas the finger at Seumas 'Seumas' finger'




$$
\text { “adger cjl" — 2016/11/28 - 11:36 - page } 9 \text { - \#9 }
$$

The difference here between 'finger' and 'heart' appears to be uniqueness, similar to the difference in English between 'the finger I hurt' vs 'the heart I hurt', where the latter loses its possessive bodypart reading. We see a similar pattern for non-unique kinship terms:
a. bràthair Sheumais brother Seumas.GEN
'Seumas' brother.'
b. ??am bràthair aig Seumas the brother at Seumas for 'Seumas' brother.
c. bràthairean Sheumais brother.PL Seumas.GEN 'Seumas' brothers.'
d. na bràthairean aig Seumas the brother.PL at Seumas for 'Seumas' brothers.

Again the difference between 'the brother' and 'the brothers' appears to be related to uniqueness. The following is generally considered unacceptable:
(24) *a’ mhàthair aig Mòrag the mother at Morag 'Morag's mother'

This means that we effectively have some constrained variability in the system. Inalienably possessed but non-unique elements allow both structures with, according to my consultants, no detectable difference in meaning ((23-c-d) and (24-c-d)). We capture this distribution in the analysis partly via the semantics of POSS. The various details about definiteness are not crucial to the rest of the analysis here (see Adger 2013 for discussion).

For alienables, the genitive structure is extremely high register. (25) is strikingly odd in spoken Gaelic, and even in most written registers.

$$
\begin{aligned}
& \text { a. peann Sheumais } \\
& \text { pen Seumas.GEN } \\
& \text { 'Seumas' pen' } \\
& \text { b. a pheann } \\
& \text { his pen } \\
& \text { 'His pen' }
\end{aligned}
$$

In vernacular speech, then, variability is restricted to inalienably possessed but nonunique elements.

Given the various components of the structure just motivated, Adger 2013 suggests a way of structurally unifying the two possessive strategies as follows. 


$$
\text { "adger"cjl" — 2016/11/28 - 11:36 — page } 10 \text { — \#10 }
$$

Barker (1995) and many others argue for the existence of a semantic function that has a generalized relational semantics, pragmatically determined, which is used to capture the wide range of meaning relations in the English genitive construction.

\section{Anson's ball}

The relation between Anson and ball can be any pragmatically reasonable one: Anson could own the ball, have just kicked it, be temporarily holding it, etc. This same range of relations is available for the prepositional possessor in Gaelic, motivating this general relational semantics for the semantics for POSS that occurs in the prepositional possessive construction.

This gives us two varieties of the category POSS: one is phonologically zero, lacks unvalued agreement features, and has a restricted set of semantic relations associated with it (the lexical item introducing the KIN relation we saw above). The other, in the unified analysis, bears agreement features, has a general relational semantics, and is realised via the usual morphology of the preposition aig. I give the version for first singular generalised possessor for concreteness.

$$
\begin{aligned}
& \text { a. } \emptyset:: \operatorname{POSS}:: \lambda x \lambda y \cdot \operatorname{KIN}(\mathrm{x}, \mathrm{y}) \\
& \text { b. agam::POss[sg:+,part:+, auth:+ ]:: } \lambda x \lambda y \cdot R(x, y) \text {. }
\end{aligned}
$$

The same basic syntax that we used for mo bhràthair is sufficient to capture am bràthair agam, which is literally 'the brother at-me', using the generalised possessor instead of the specific kinship possessor. ${ }^{3}$

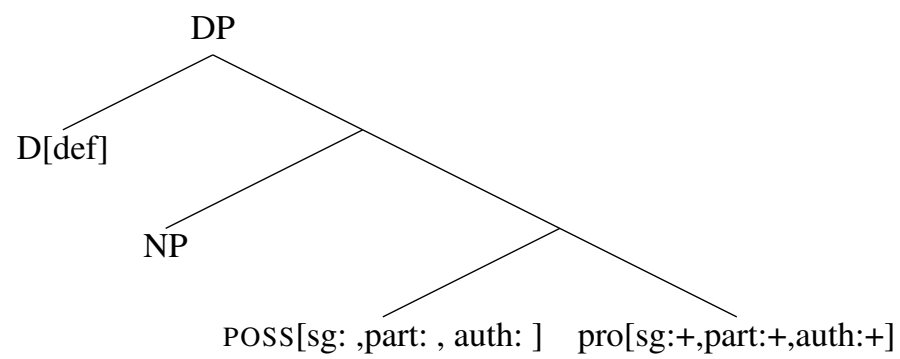

Here it is POSS that will agree with pro, licensing it, rather than D. It follows from the fact that pro is then licensed that D can have no agreement features (or else we would have double agreement, something which is not used for the licensing of pro) and a simple definite article is the only available item that will be syntactically well formed ${ }^{4}$.

\footnotetext{
${ }^{3}$ Adger 2013 places these two different types of POSS in two different syntactic positions to capture various constituency effects, but that distinction is not relevant here.

${ }^{4}$ Definite determiners in Gaelic do show concord in case, number and gender with their noun, but person ([part: \pm$]$ ) is not marked on such determiners, so they constitute a separate morphosyntactic class.
} 
Using the generalized possessor POSS rather than the kinship POSS, am bràthair agam is derived as follows:

(29)

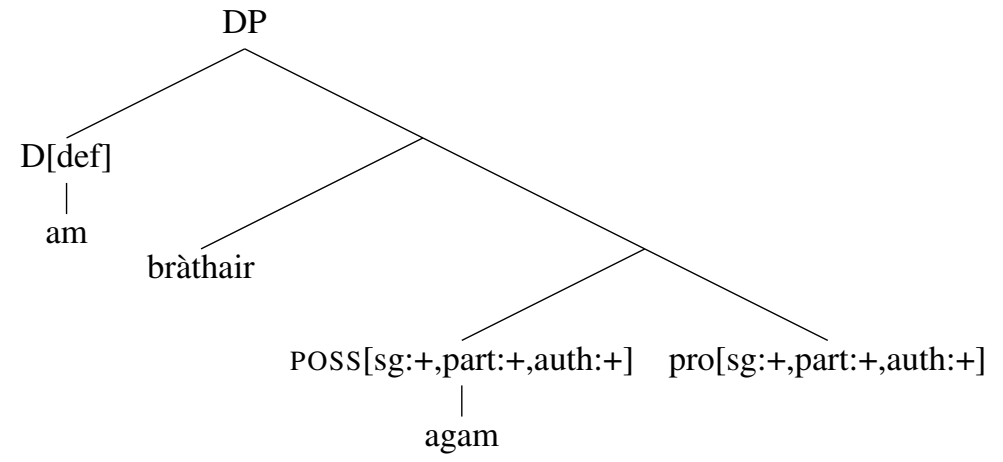

The definite article introduces an iota operator in the semantics, and the POSSP combines with the head noun by predicate modification, deriving a meaning for this as follows.

$$
\imath \mathrm{x} . \text { brother }(\mathrm{x}) \wedge \mathrm{R}(\mathrm{x}, \text { speaker })
$$

The pragmatics of the situation resolve the $\mathrm{R}$ relation to one of kinship under usual contexts (or to another pragmatically relevant relation).

This system derives the range of form-meaning relationships in the vernacular Gaelic possessive straightforwardly (the high register written varieties simply lack the prepositional version). I give examples here for versions of 'her brother/pen'.

$$
\begin{aligned}
& \text { a. } \mathrm{D}[\mathrm{sg}:+ \text {,part:-, fem: }+] \text { brother POSS pro } \\
& \text { a bràthair } \emptyset \quad \emptyset \\
& \imath \mathrm{x} . \operatorname{brother}(\mathrm{x}) \wedge \operatorname{KIN}(\mathrm{x}, \mathrm{y}) \text {, where y is an identifiable female. }
\end{aligned}
$$

b. $\quad \mathrm{D}[\mathrm{def}]$ brother POSs[sg:+,part:-, fem:+] pro am bràthair aice $\emptyset$ $\iota \mathrm{x}$. brother $(\mathrm{x}) \wedge \mathrm{R}(\mathrm{x}, \mathrm{y})$, where $\mathrm{y}$ is an identifiable female. $\mathrm{R}$ is resolved pragmatically

c. D[sg:+,part:-, fem:+ ] pen POSs pro a peann $\emptyset \quad \emptyset$

$\imath \mathrm{x} \cdot \operatorname{pen}(\mathrm{x}) \wedge \mathrm{KIN}(\mathrm{x}, \mathrm{y})$, where $\mathrm{y}$ is an identifiable female. Pragmatic clash.

d. D[def] pen Poss[sg:+,part:-, fem:+] pro

am peann aice

$\emptyset$

$\imath \mathrm{x}$. pen $(\mathrm{x}) \wedge \mathrm{R}(\mathrm{x}, \mathrm{y})$, where $\mathrm{y}$ is an identifiable female. $\mathrm{R}$ is resolved pragmatically. 


\subsection{Change in ESG possessives}

Let's now turn to the changes Dorian reports for ESG. As I mentioned in the first section, Dorian reports that her fluent speakers appear to know the relevant possessive forms, though, except for what Dorian takes to be fixed expressions, they are not easily accessible. The younger speakers generalise the prepositional possessive strategy throughout, and Dorian reports that these speakers even seem unaware of the relevant proclitic forms. It's worth quoting the relevant passage from Dorian 1973, page 419 , in full (footnote 12 included in the quote, footnote 13 ommitted as not relevant here):

"The full range of possessives, with appropriate mutations or lack of mutation, can be elicited from older speakers, and even occasionally from some younger speakers, in only one environment other than the passive: fossilized fixed expressions involving kinship terms ('when our father was alive'), body parts ('at her back', i.e. 'behind her'), or other inalienables ('they lost their lives'). Outside these fixed expressions, the pronouns of the 1st and 2nd singular occur freely ${ }^{12}$ but the other singulars typically, and the plurals invariably, are replaced by an alternative possessive structure involving the definite article and the preposition aig /ig/ 'at', which conjugates for person. Thus with a clothing term, e.g., we would typically get a syntactically suppletive paradigm:
kač ən $^{N}$ bel mə ${ }^{L}$ pečan ${ }^{13}$
kač on $^{N}$ bel d ${ }^{L}$ pečan
'Where is my sweater?'
kač $ә n^{N}$ bel $\partial^{N}$ pečan ik
'Where is your-sg. sweater?'
kač ən $^{N}$ bel $\partial^{N}$ pečan $\varepsilon k$
'Where is the sweater at-him?'
and so forth through a plural formed with the aig-construction exclu- sively.
12 I.e., they occur freely within the semantic range open to possessives in ESG, chiefly inalienables and things that can be worn or carried on the person. If the noun modified does not fall into this semantic range, the alternative aig-construction will be used."

For Dorian's younger speakers even the first and second singular give way to the prepositional strategy, so that the alienable/inalienable distinction is no longer grammatically marked. Why should this be the change that happens here? Dorian later suggested that it may be because the alienable/inalienable distinction is not strong elsewhere in the grammar of the language. The use of possessive clitics is

tied to a distinction not productively necessary to any other lexical or morphological choice in the language, namely (roughly stated) alienability vs. inalienability in nouns. A distinction without any overt marker of its own, revealing itself only in one lexical/syntactic choice, may be a candidate for early loss, even when the result seems "perversely" noncongruent. (Dorian, 1989, 6)

This proposal indeed leads to the expectation that one of the two structures would be lost, but does not explain which one should be lost. It requires us to assume that 


$$
\text { "adger"cjl” — 2016/11/28 - 11:36 — page } 13 \text { — \#13 }
$$

there is something marked about 'inalienability' which is not marked for 'alienability', such that the former is lost and the latter maintained. Without some further stipulation, this proposal doesn't lead to an explanation of why the maintained structure is not analogous to English, the speaker's other language. Why do we find an leabhar agam, literally, 'the book at me' rather than *mo leabhar, analogous to 'my book'? More generally, why do the structures not converge to the structure of what is, for the younger speakers, the dominant language_English (Winford 1993)?

The answer is twofold: first, the richness of phonological forms associated with different values of agreement features reduces, leading to a reduction in the features themselves; second, reduced agreement features pose a problem for licensing pro, and the solution is given by what other resources are available in the language to express the relevant meanings. In the case at hand, the prepositional possessor can be used to express anything that the inalienable possessor can express, so there is a route to solving the problem raised by licensing pro in inalienables which is to use a structure that does the job, even though that structure is quite unlike possessives in English, the speakers' dominant language.

The lexical forms found for the ESG proclitics, which Dorian reports are available in fixed expressions, are as follows:

ESG Possessive Proclitic Paradigm

$\begin{array}{llll} & & \mathrm{Sg} & \mathrm{Pl} \\ \text { 1st Person } & & \text { mo } & \text { na } \\ \text { 2nd Person } & & \text { do } & \text { na } \\ \text { 3rd Person } & \text { masc. } & \mathrm{a}^{L} & \mathrm{an}^{N} \\ & \text { fem. } & \text { a } & \mathrm{an}^{N}\end{array}$

We can see that there are syncretisms already evident in the plural. ESG is distinct from Western varieties of Gaelic in not distinguishing 1st plural from 2nd plural (in Western Gaelic this would be $a r$, vs. $u r$, while these have been neutralised to $n a$ in ESG). The morphological distinctions motivate a less rich set of D's than is available in Western varieties:

Morphosyntactic features for possessive proclitics in fixed expressions

$\mathrm{Sg}$

1st Person
2nd Person
3rd Person

Given Dorian's outline of the changes, for all speakers only the first and second persons have an accessible phonology outside these fixed expressions. For ESG, then, D ends up having the following relations between the features and the phonology:
Morphosyntactic features for possessive proclitics outside fixed expressions 


$\begin{array}{llll} & & \text { Sg } & \text { Pl } \\ \text { 1st Person } & & \text { [part:+, sing:+, auth:+] } \leftrightarrow \text { mo } & \text { [part:+, sing:-] } \\ \text { 2nd Person } & & \text { [part:+, sing:+, auth:-] } \leftrightarrow \text { do } & \text { [part:+, sing:-] } \\ \text { 3rd Person } & \text { masc. } & \text { [part:-, sing:+, fem:-] } & \text { [part:-, sing:-] } \\ & \text { fem. } & \text { [part:-, sing:+, fem:+] } & \text { [part:-, sing:-] }\end{array}$

The absence of the $\leftrightarrow$ symbol here expresses the lack of a phonological form for this feature specification.

There are, then, two aspects to feature loss here. One is the existence of a reduced morphosyntactic feature set compared to other varieties of Gaelic (including earlier varieties of the language). The other is related to an inability to access phonological forms for the feature bundles, a result of reduced exposure to the full range of morphological forms during acquisition. For these speakers, although pro can be syntactically licensed, there is simply no phonological way of expressing its licenser. However, D is obligatory in Gaelic noun phrases, leading to a problem of how to express the structure.

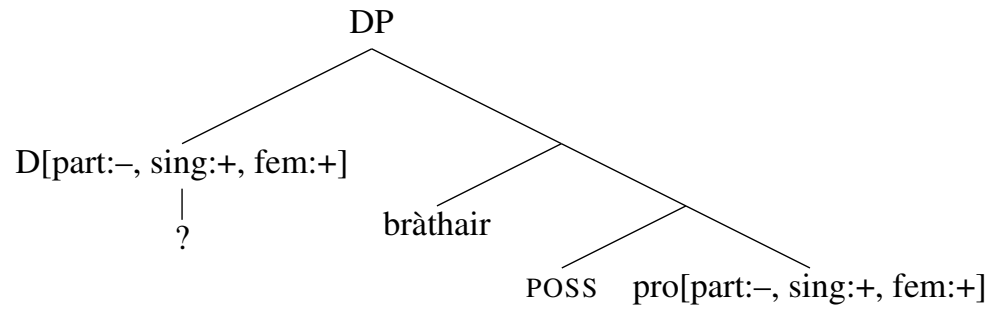

This weakening of feature specification can be seen as part of the same change that has already gone to completion with the objects of non-finite verbs. Recall that in other varieties of Gaelic aspectual elements inflected for agreement features, but ESG instead uses an overt pronoun:

An robh a' ghrian gan dalladh?

Q PST be.PAST the sun SIMP.3PL blind.vN

'Was the sun blinding them?'

Western Gaelic

An do robh a' ghrian dalladh iad

Q PST be.PAST the sun blind.VN them

'The sun was blinding them.'

ESG

We can understand this as a variation in the range of categories that can be specified with licencing agreement features. Western varieties of Gaelic have the relevant features on the element that signifies simple aspect. ESG has lost that specification entirely, so that pro cannot be licensed in object position of non-finite verbs, leading to a grammatical difference between the varieties. The solution in the aspectual constructions is to use an overt pronoun. The same loss appears to be extending to $\mathrm{D}$ in possessives. At the point of Dorian's fieldwork, aside from fixed expressions, the only two versions of $\mathrm{D}$ which have a phonological form are those that express the difference between first and second person. 


$$
\text { "adger cjl” — 2016/11/28 - 11:36 — page } 15 \text { — \#15 }
$$

This proposal gives us a model for Dorian's observation that the older fluent speakers had difficulty in accessing the relevant possessive $\mathrm{D}$, even though they could, with effort, access the right form. That would suggest a cognitive organization of the feature matrix above, where although the items are grammatically available, they are close to impossible to access (one could model this via a probabilistic version of lexical access). However, as the next generation acquires the language, if there is not sufficient data to give them access to the forms, the relevant feature specifications are simply never acquired and language change takes place: the feature matrices are simply not associated with a phonological form. As the change progresses, the version of $\mathrm{D}$ bearing the relevant features is totally lost, leading to an inability to license pro.

If the language loses agreement feature specification over time, then, given that pro needs agreement features to be present in the structure in order to be licensed, what are the implications? One might guess that the grammar would just break down here, and the speakers would have only a fragmentary system, but that is not what Dorian reports for even the young speakers. Another possibility would be for speakers to reanalyse the proclitics, not as agreeing Ds, but rather as full pronouns, following the model of English, and this appear to be what has happened in the aspectual construction.

One might imagine, analogizing with the extant aspectual construction, that the language would resort to an overt pronoun, perhaps moving this to the prenominal position under pressure to converge with English. Such a reanalysis would result in structures such as the following:

$$
\begin{aligned}
& \text { *iad bràthair } \\
& \text { them brother } \\
& \text { 'their brother' }
\end{aligned}
$$

However, this did not happen, and the question is why.

The explanation I propose here appeals to the internal workings of the language as opposed to external pressure from English. Recall that the prepositional POSS item, which competes for the same structural position as the inalienable POSS item, semantically subsumes it: inalienable POSS is a hyponym of prepositional POss, which can be used for inalienables as well. Since the range of possible uses of the prepositional POSS category semantically contains the range of use of the inalienable POSS category, speakers acquiring it maintain full expressive capacity: they can say all the things they need to say.

Consider a situation of normal acquisition of the Western Isles structure. Here the child has to figure out that there are two lexical items that express possessive relationships in the syntax: one is usable for almost all possessive relations, while the other is usable for a narrower range of kinship and bodypart relations. Following the idea that the learning mechanism posits as few featural distinctions as it can, a child will conservatively posit just one of the two possible POss heads. Say she posits the narrower one, then general facts about what the child wants to express will immediately require her to also adopt the broader one, simply to deal with inalienables. If, on 
the other hand, she posits the more general one, the data will, at some point, suggest that there is a bifurcation in the feature space. The child will notice that a cognitively important category, plausibly available as part of UG, will consistently correlate with one structure, while the other structure is available for all kinds of possession. Since there will be sufficient data to suggest a one to one match between proclitic possessive syntax and unique kin or bodyparts, the child will posit two lexical items for possession in the language, the two we have seen above.

However, in a situation of reduced input, such as when a language is obsolescing, if the child posits the more generally applicable lexical item, there will simply not be enough data to, in addition, posit the more specific lexical item. Further, the general lexical item will perform all of the expressive linguistic tasks that the speaker needs, so the speaker is not left with any gaps in their expressive capacity. Of course the child will encounter a small number of cases where the possessive proclitics are found, but these can be learned as exceptions or idiomatic special cases, as Dorian suggested. Dorian 1975 provides some evidence that even in fixed expressions certain forms (the special form of the feminine singular preceding a vowel, for example) are lost, leaving lexical gaps. This proposal follows Yang's suggestion that there is a quantity threshold for when a child posits a rule (Yang 2005). In the case of ESG kinship possessives, my proposal is that there is simply not enough data to propose the kinship Poss lexical item.

There are then four aspects of this situation that are relevant:

a. Reduction in the range of specification of agreement features, following a reduction in the range of phonological forms distinguishing agreement feature values, and hence a syntactic 'problem' with what to do with pro.

b. The generalized possessor item is morphosyntactically realised as a preposition, and prepositional agreement features are robustly present, so can step in.

c. The generalized possessor item is sufficient to accomplish all of the tasks for expressing meanings that are required of the speaker

d. In an obsolescing situation, there is not enough data to reach the threshold where a specialised kinship POSS is posited.

There is then a problem raised by structures, like (40), where the licenser of pro has no possible expression:

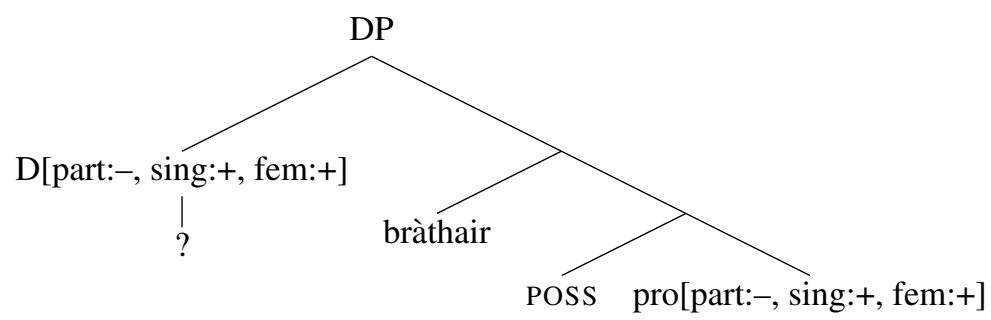


This problem is solved by using a structure where the licenser has a wider range of meanings and can be expressed.

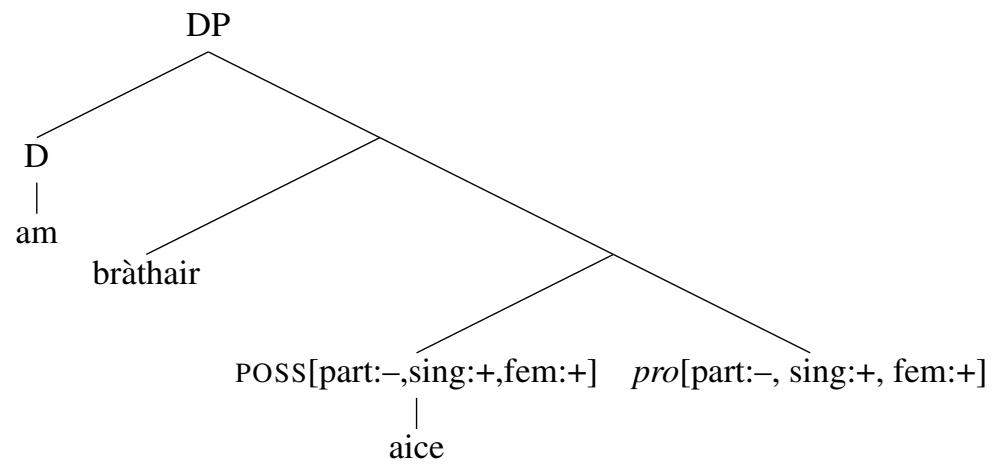

The reason that, in the possessive, speakers have not analogized to English and reanalysed the proclitic as a full pronoun is that an expressively equivalent alternative is already available. We saw that one change, a loss of agreeing aspectual particles, already completed, and in that case the solution to pro not being licensed was use of an overt pronoun. In the possessive construction, a more general structure has stepped in, so that there is still a pro, but it is licensed by prepositional inflection, an area of inflection that Dorian reports is very robust, even for her semi-speakers.

The idea that speakers opt for a more general form in situations of language change, or contact, has been proposed for other situations. Silva-Corvalán (1994), for example, reports on a situation in Los Angeles Spanish where the syntax of clitics changes for internal reasons even though it is in close contact with English.

\section{Passives}

The two kinds of passive in ESG are found throughout the Gaelic of the Western Highlands and Isles. In the passive formed using the verb dol, 'go', the lexical verb appears in a nominalized verbal form, the object appears before the nominalized verb, and they are linked by a particle $a$, which causes lenition. This particle is homophonous with the third masculine singular possessive proclitic.

Chaidh òrain Ghàidhlig a sheinn aig a' chèilidh go.PAST songs Gaelic Prt singing at the ceilidh 'Gaelic songs were sung at the ceilidh.'

I will not motivate the general constituency properties of this passive here, but rather assume that the structure is as in (43). The basic constituency of such structures is well established in Gaelic (see Adger 2010), and the precise categories are not crucial for us here, so I will simply use $\mathrm{X}$ to refer to a piece of structure whose constituency is established, but whose category is not relevant. The object moves 


$$
\text { "adger cjl" — 2016/11/28 - 11:36 — page } 18 \text { — \#18 }
$$

from the canonical object position of the nominalized verb (NV) to a higher subject position.

(43)
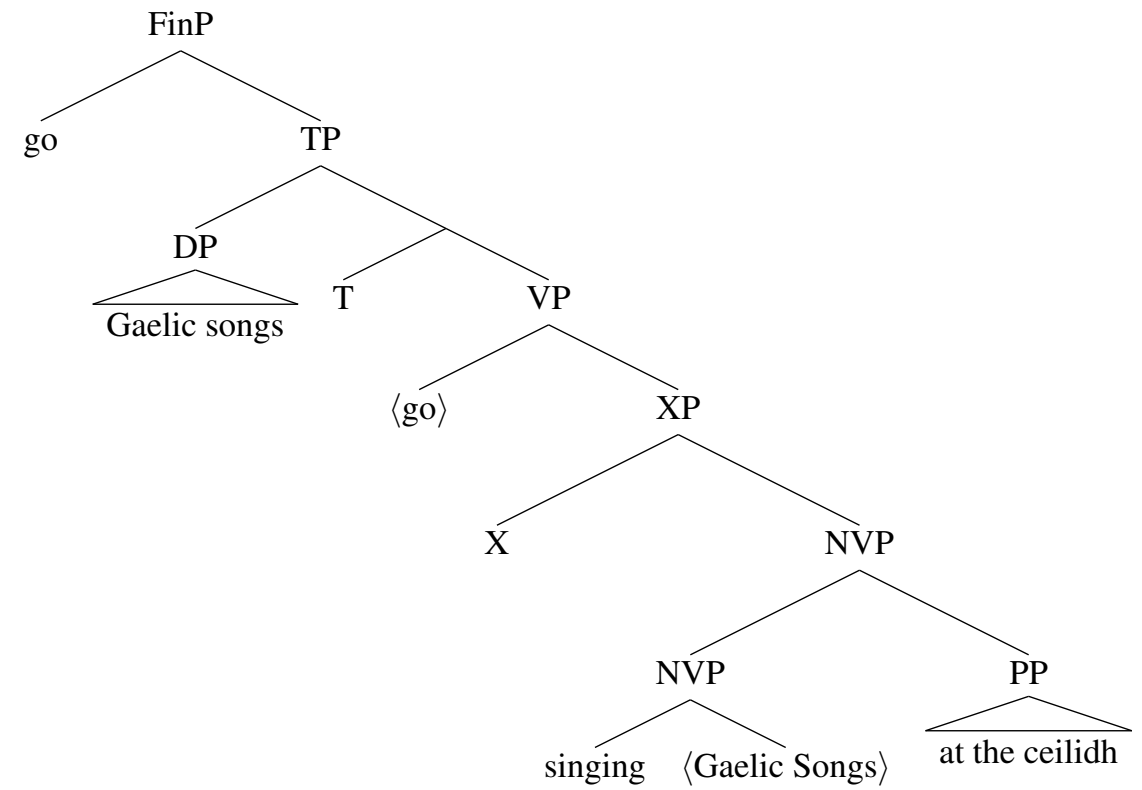

Whatever the category $\mathrm{X}$ is, it clearly expresses agreement features. When the object of the verb is pronominal, as in (44), we find the same set of forms that we found with the possessive proclitics:

(44) Chaidh an seinn aig a' chèilidh go.PAST their singing at the ceilidh 'They were sung at the ceilidh.'

Thèid mo phògadh aig a' chèilidh go.FUT my kissing at the ceilidh 'I will be kissed at the ceilidh.'

We can model this agreement in a similar way to how we modelled the possessive proclitics. The distribution of emphatic particles suggests that there is a pro in object position:

Thèid mo phògadh-se aig a' chèilidh go.PAST my kissing at the ceilidh

'I was kissed at the ceilidh.'

Given (46), there is a pro in object position, so the analysis of (44) is as follows: 


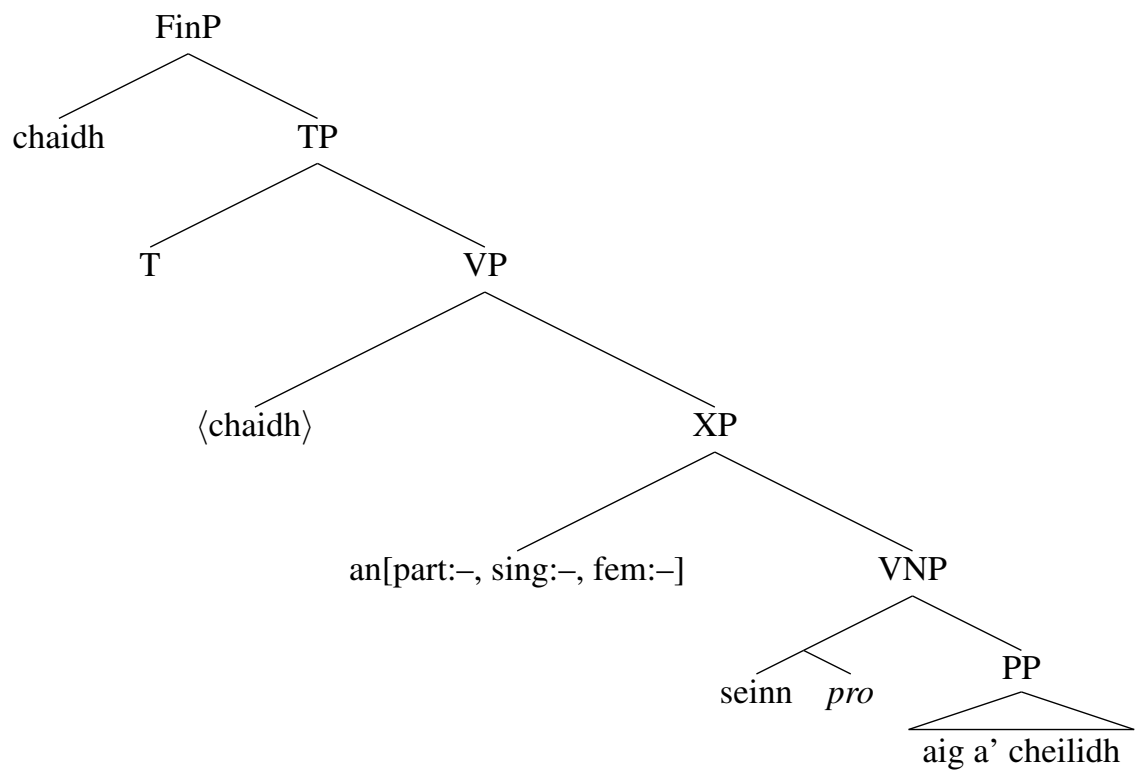

When the object is a full DP, it appears in the specifier of TP, and X does not mark agreement features (presumably as there is no pro in the structure). So we have a number of morphological forms for $\mathrm{X}$, depending on how its feature content is valued, which should be, by now, familiar.

$$
\begin{aligned}
& \text { a. an::X[part:-, sing:-, fem:-] } \\
& \text { b. mo::X[part:+, sing:+, auth:+] } \\
& \text { c. etc. }
\end{aligned}
$$

This general syntax is similar to the agreeing D we saw with possessives, though XP doesn't have the distribution of a DP (for example, XP cannot be a subject), and X, when it is unspecified for agreement features, appears as the third masculine singular form, not as a definite article. This is motivation for saying that $\mathrm{X}$ is different from $\mathrm{D}$, even though the mechanisms whereby that category enters into relationships with other categories are very similar to what happens with D.

We have seen two areas of the grammar of ESG where quite radical restructuring took place in how null pronouns are licensed: sometime before Dorian began her fieldwork, pro in the object position of non-finite verbs was replaced by an overt pronoun, and agreement features that had been proclitic to the verb were lost. In possessive constructions agreement features in D were lost, so that they could no longer license a pro possessor, with the result that the pro is instead licensed by an inflecting preposition. Dorian 1973 reports a change in the go-passives across the generations. The oldest fluent speakers have a Western Isles like go-passive. On the analysis proposed here, this involves agreement features present on $\mathrm{X}$, licensing a pro object: 
However, just as we saw with D, unvalued agreement features are, over the timescale of Dorian's fieldwork, also being lost on X. If X loses agreement features, then the same issue arises as we addressed above: what is to be done with pro? For the 'go'passives, a simple solution is that the object pronoun appears as an overt pronoun and so we might expect an overt pronoun to appear after the verb:

(50) *Chaidh a bhathadh iad anns an loch go.PAST PRT drown.VN they in the loch 'They were drowned in the loch.'

However, a robust syntactic pattern in ESG is that overt objects prepose to a preverbal position in passives as we saw in (43); this is part of the syntactic ecology of the language. This rule of ESG grammar is not being lost. It requires the overt object pronominal to prepose, and this is exactly what Dorian reports the change is:

Chaidh iad a bhathadh anns an loch go.PAST they PRT drown.VN in the loch 'They drowned in the loch.'

This development is treated by Dorian as an analogy to the overt subject appearing in the pre-verbal possition in ESG 'be'-passives (as in example (7) and discussed immediately below), and in some sense it is. However, rather than being a result of a simple surface positioning effect, it should be thought of as part of the same system that already reached completion with objects of non-finite active verbs (overt pronoun used rather than pro), interacting with an independent and robust syntactic pattern in the language. The dependency between agreement features on a licenser and a null pronoun is replaced by a lack of features and an overt pronoun. In the case of the passive, however, the overt pronoun moves to a preverbal position, just as an overt DP does. 


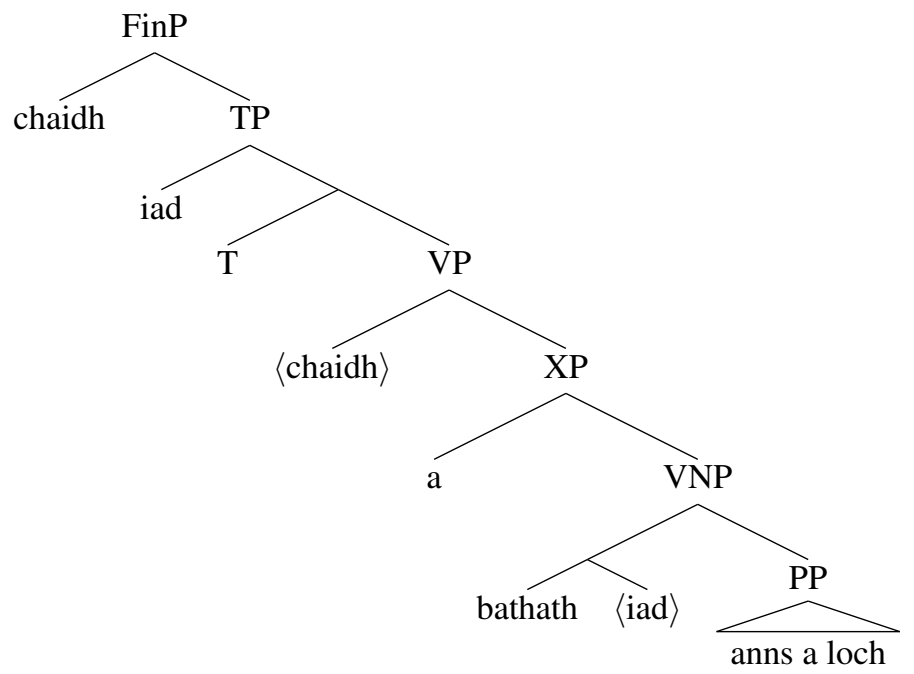

Consider the following table of changes in the 'go'-passive across the generations adapted from Dorian 1973, page 422, showing a change in form in the total number of 'go'-passives:

$\begin{array}{lllll}\text { Age Group } & \% \text { Proclitic Only } & \% \text { OvertPro Only } & \% \text { OvertPro+P } & \text { Total } \\ 80 \mathrm{~s} & 100 & 0 & 0 & 9 \\ 70 \mathrm{~s} & 68 & 27 & 1 & 22 \\ 60 \mathrm{~s} & 52 & 10 & 38 & 21 \\ 50 \mathrm{~s} & 27 & 19.5 & 53.5 & 41 \\ 40 \mathrm{~s} & 0 & 22 & 78 & 37\end{array}$

The most conservative structure, with the proclitic agreement licensing pro, declines dramatically. It is partly replaced by the structure where the pronoun argument is made overt, and moved to the preverbal object position, in the older (70s) speakers. However, an alternative structure (the third column, under OvertPro+P) also comes into play. This structure looks as follows:

(54) Chaidh iad air a bhathadh anns an loch go.PAST they PERF PRT drown.VN in the loch 'They drowned in the loch.'

Here the overt pronoun appears followed by an aspectual particle. This is unexpected from what we have said so far.

In addition to the 'go'-passive, ESG (and Western Gaelic) has a 'be'-passive. This involves the suppletive auxiliary bith which occurs with a subject and an aspectual phrase, marking perfect aspect semantics. 


$$
\text { "adger"cjl” — 2016/11/28 - 11:36 — page } 22 \text { — \#22 }
$$

(55) Tha an doras air a dhùnadh.

Be.PRES the door PERF PRT close.VN

'The door has been shut/is shut.'

In Western varieties of the language, the particle immediately preceding the verb shows agreement for the object which has been promoted to subject position:

$$
\begin{aligned}
& \text { Tha a' chaileag air a pògadh. } \\
& \text { Be.PRES the girl PERF PRT.3FS kiss.VN } \\
& \text { 'The girl has been kissed.' }
\end{aligned}
$$

These are passive in meaning, but note that there is agreement with the (moved) object, so they are transitive in form. In fact, (56) has a perfectly legitimate active transitive meaning: 'The girl has kissed her.'

As I mentioned earlier, when X occurs with an overt noun phrase in a go-passive, it appears in a default form with no agreement features. However, in the be-passive, it appears with agreement features:

$$
\begin{aligned}
& \text { a. Chaidh na balaich a phògadh } \\
& \text { go.PAST the boys PRT.3SG kiss.VN } \\
& \text { 'The boys were kissed.' } \\
& \text { b. Bha na balaich air am pògadh } \\
& \text { be.PRES the boys PERF PRT.3PL kiss.VN } \\
& \text { 'The boys were kissed.' }
\end{aligned}
$$

This is slightly mysterious, in that, until now, we've seen agreement features only in situations where they license pro. However, agreement features also appear in passive participial constructions in many languages, and Kayne (1989) has suggested that this arises just when the overt object moves through the specifier of an agreement bearing participial head. Adopting this idea, the structure for the 'be'-passive is minimally different from the 'go'-passive: 


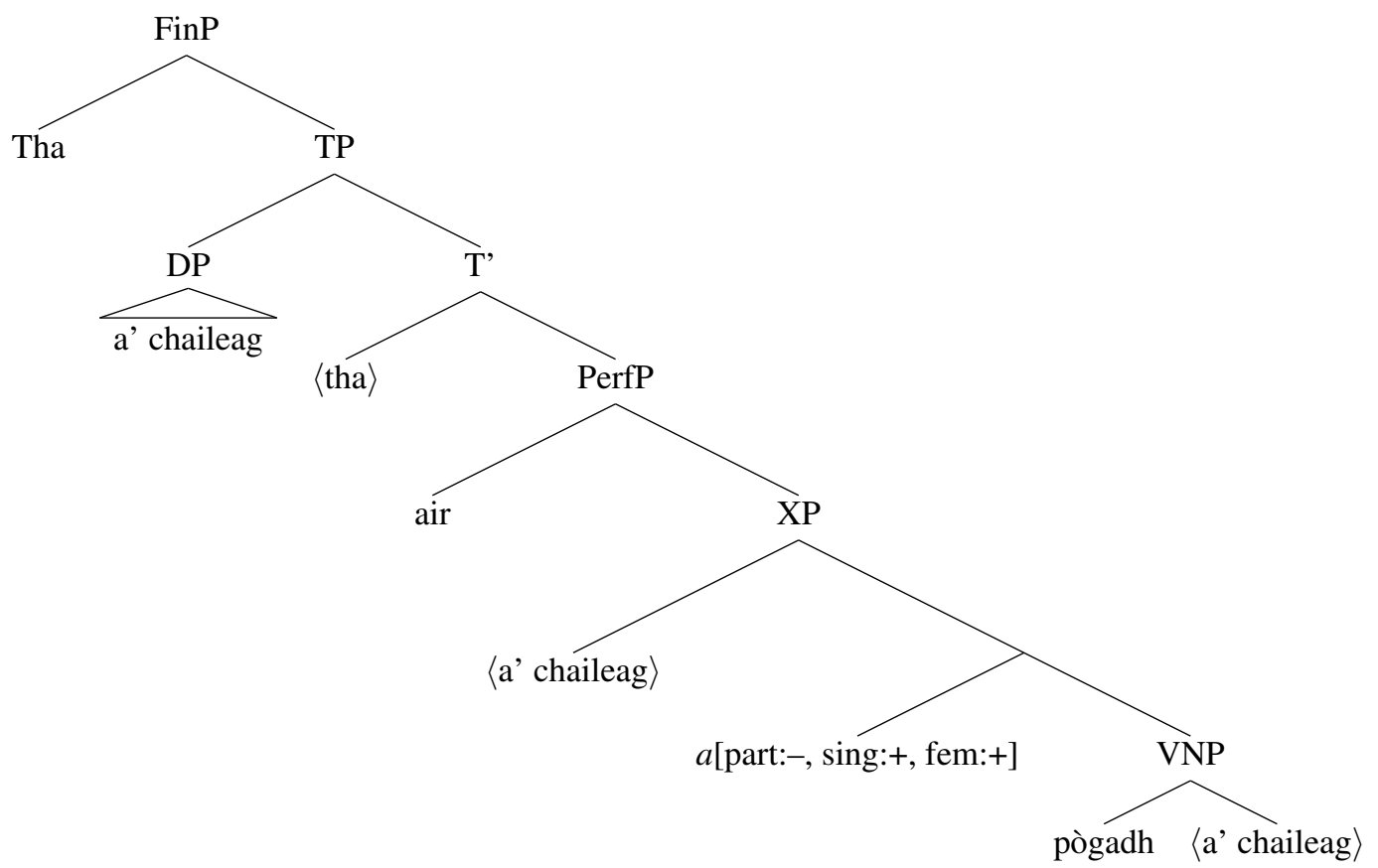

Dorian reports that her older speakers have no problems in producing any of the relevant agreeing forms in 'be'-passive (unlike what we saw with the possessive proclitics). They form be-passives in a way that is identical to Western Isles Gaelic.
a. Bha iad air an cumail be.PAST they PERF PRT.3PL keep.VN 'They were kept.'
b. Bha i air a cumail be.PAST she PERF PRT.3SF keep.VN 'She was kept.' be.PAST it PERF PRT.3SM keep.VN 'It was kept.'
c. Bha e air a chumail

ESG

However, Dorian reports an age effect of this phenomenon. Younger speakers have a variant where no agreement takes place, and we find the same proclitic with all forms:

$$
\begin{aligned}
& \text { Bha iad/i/e air a chumail } \\
& \text { be.PAST they/she/he PERF PRT.3SM keep.VN } \\
& \text { 'They, she, him were/was kept' }
\end{aligned}
$$

Dorian suggests that this is because of a redundancy between the specification of the subject and the appearance of the relevant features on the object. However, she 


$$
\text { “adger cjl” — 2016/11/28 - 11:36 — page } 24 \text { — \#24 }
$$

doesn't report that there is loss in the first and second person for these 'be'-passives, and the first and second person are equally redundant.

I'd like to suggest instead that loss of agreement here is just because the same category $(\mathrm{X})$ is involved as a subpart of both kinds of passives. As we saw earlier, agreement features on $\mathrm{X}$ are being lost, so that 'go'-passives are unable to license pro objects. The 'be'-passive never involves a pro-object even when the object is pronominal (it involves true movement of the object, so, in technical terms, there is a copy (what used to be called an NP-trace) in the object position, not a pro). However, that is irrelevant here. If $\mathrm{X}$ is losing agreement features, then we expect there to be a loss of overt morphosyntactic distinctions marked preverbally in the 'be'-passive, which is exactly what we see.

There is one question remaining, though, which is why there is the innovation of the mixed version of the 'go'- and 'be'-passives. That is, why do speakers begin to use examples like (61)?

$$
\begin{aligned}
& \text { Chaidh iad air a bhathadh anns an loch } \\
& \text { go.PAST they PERF PRT drown.VN in the loch } \\
& \text { 'They drowned in the loch.' }
\end{aligned}
$$

In fact, as we saw in the table in (53), these innovative structures rise rapidly to become the most used variant in Dorian's data. Why should this be? The answer is the same answer that I gave for why the prepositional possessive replaced the proclitic possessives: a hyponymic relationship between the variants - the 'be'-passive semantically subsumes the 'go'-passive, which means that it can be used in all the circumstances that the 'go'-passive can. The 'be'-passive structure then encroaches on the 'go'-passive structure, leaving the morphological forms for 'go' and 'be' as straightforward variants.

Let's briefly look at the semantic interpretation of the two types of passive in Western Gaelic to show that the 'be'-passive does indeed semantically subsume the 'go'-passive. 'Be'-passives in Gaelic can be used for either event or state readings, similarly to the passive in English.

$$
\begin{aligned}
& \text { a. The door was closed abruptly (event) } \\
& \text { b. The door was closed for three years (state reading prominent) } \\
& \text { c. The door was closed abruptly for three years (repetitive reading only) }
\end{aligned}
$$

When modified by an adverb, the event reading in an English passive is prominent, while a durative prepositional phrase favours (but does not force) a state reading. When both are combined, we find that the most prominent reading is a repetitive one where the same abrupt event takes place for three years. Both readings are available for the passive in English, with pragmatics leading to different readings being prominent, depending on modifiers of the event.

We find the same ambiguity with the 'be'-passive in Gaelic: 
(63) Tha an uinneag air a dhùnadh fad dà uair a thìde

Be.PRES the window PERF PRT.3FS close.VN for two hours

'The state of closedness of the window lasted two hours.'

'The event of closing the window took two hours.'

However, the 'go'-passive is unambiguous - it only involves the event reading.
Chaidh an uinneag a
dhùnadh fad dà uair a thìde
go.PAST the window PRT.3FS close.VN for two hours
'The event of closing the window took two hours.'

Other tests for stativity lead to the same conclusion. The 'be'-passive but not the 'go'passive is compatible with adverbs like 'still' which modify the state that obtains after the event has completed.

Tha an doras air a dhùnadh fhathast

Be-PAST the door ASP Prt close-VN still

'The door has been shut/is shut still'

(66) *Chaidh an doras a dhùnadh fhathast

Be-PAST the door Prt close-VN still

'The door has been shut/is shut still'

There's also an effect on the interpretation of temporal clauses. A 'when'-clause with a 'be'-passive specifies a point in time, while a 'when'-clause with a 'go'passive specifies a causal event. In English, get-passives are perhaps the closest to a 'go'-passive in Gaelic, though they are by no means identical.

(67) Nuair a thàinig sinn dhachaigh, bha an uinneag air a bhriseadh When that arrived we home, was the window ASP Prt break-VN 'When we arrived home, the window was broken.'

(68) Nuair a shleamhnaich am fàradh, chaidh an uinneag a bhriseadh When that slipped the ladder, went the window Prt break-VN 'When the ladder slipped, the window got broken.'

The fact that 'be'-passives can have a stative reading allows them to function adjectivally, as in:

(69) Òran air a dheagh-ghabhail song ASP Prt well-sung

'A well-sung song.'

No such possibility is available for 'go'-passives.

The data just presented suggest that the 'be'-passive semantically subsumes the go-passive, just as the generalised possessor subsumes the kinship possessor semantically. We should therefore expect, if there is change in this area of the grammar, it should be in the direction of the 'be'-passive. This is exactly what the table in 
(53) shows, with the prepositional element of the 'be' passive appearing with both 'be' and 'go' auxiliaries, and amounting to almost $80 \%$ of the forms in the youngest generation.

Reviewing where we have come to, we can see that there are a number of changes which have either taken place or were taking place during Dorian's fieldwork. All of these changes can be traced back to a reduction in agreement features and hence issues in licensing pro. It is instructive to compare these structures with the structures found in Western varieties of Gaelic:

\begin{tabular}{l|lll} 
Construction & ESG & Western Gaelic & Translation \\
\hline object of verb-noun & dalladh iad & gan dalladh & blinding them \\
possessives & am peitean aice & a pheitean & her jersey \\
go-passive & chaidh iad a bhathadh & chaidh am bhathadh & they got drowned \\
be-passive & Bha i air a chumail & Bha i air a cumail & she was kept
\end{tabular}

What is even more striking is that these are almost all the areas in Gaelic grammar where agreement features are implicated, except for prepositional agreement, where the morphology in ESG is robust ${ }^{5}$.

\section{Conclusion}

What I hope to have done in this paper is to show that the changes reported by Dorian in her foundational work on ESG are all rooted in a single abstract change: a loss of agreement features and concomitant effect on licensing pro. In addition, I attempted to make an argument about how a syntactic analysis of the forms available in a language can provide an explanation not for why a language begins to change but for why the changes go in the direction they do. The reduction in the range of agreement features in ESG led to a change in the syntax of non-finite verbs in simple aspect so that a new structure with verb-pronoun order appeared. The same reduction also led to a change in the possessive system, with a loss of the system marking inalienables differently from alienables, since the latter construction took over the syntactic job that was no longer being done by the former. This same reduction also led to the appearance of preverbal overt pronouns in 'go'-passives, and a loss of overt morphological agreement distinctions in 'be'-passives. I further suggested that the fact that 'be'-passives could be used to express a wider range of meanings than 'go'-passives allowed speakers to maintain a semantially expressive system, while

\footnotetext{
${ }^{5}$ The only other possible case is a single inflectional form, the first person singular conditional, which in both ESG and Western Gaelic involves the affix -inn on a finite verb. These are frequent, and don't seem to be being lost. However, it may be the case that these forms are not best analysed as involving a pro, but rather an allomorphy effect, where the subject clitic takes on a special form when attached to this mood. This is the analysis given in Adger (2000).
} 
essentially replacing 'go'-passives with 'be'-passives, unifying at an abstract level the reasons for the direction of change in both possessives and passives.

There are of course other explanations for the direction of language change. In a circumstance like that of ESG, one might expect the prestige language to exert pressure on the structures of the less dominant language, but the evidence from possessives in ESG suggests that is not what is going on here. Further, Dorian (1981) notes that only a few individuals in the community are notorious for speaking “darn’ leth Gàidhlig, darn’ leth Beurl” (half Gaelic, half-English), suggesting that codeswitching is not a major factor in the changes we see. The syntactic explanation presented here therefore seems to be broadly applicable across the structures of ESG, and, to the extent that it is successful, argues against any direct transference of structure from English to ESG for these, the major syntactic changes noted by Dorian. Of course, it may be that the loss of the agreement features in ESG, and the concommitant reduction in the distribution of pro may, ultimately, be an effect of speakers acquiring and using English in preference to Gaelic, but if this is so, then it would be at an abstract systemic level best modelled by the nature of the feature specification of functional elements in the grammar.

\section{REFERENCES}

Adger, David. 2000. VSO clause structure and morphological feature checking. In Syntactic categories, ed. Robert Borsley, 79-100. New York: Academic Press.

Adger, David. 2010. The syntax of Scottish Gaelic. In The Edinburgh Companion to the Scottish Gaelic language, ed. Moray Watson and Michele MacLeod. Edinburgh University Press.

Adger, David. 2013. A syntax of substance. Cambridge, MA: MIT Press.

Barker, Chris. 1995. Possessive descriptions. Stanford University: CSLI Publications.

Dorian, Nancy. 1973. Grammatical change in a dying dialect. Language 49(2): 413-438.

Dorian, Nancy. 1978. East Sutherland Gaelic. Dublin: Dublin Institue for Advanced Studies.

Dorian, Nancy. 1981. Language death: The life cycle of a Scottish Gaelic dialect. Philadelphia, PA: University of Pennsylvania Press.

Dorian, Nancy. 1989. Introduction. In Investigating obsolescence, 1-10. Cambridge, U.K.: Cambridge University Press.

Hale, Ken and James McCloskey. 1984. On the syntax of person-number inflection in Modern Irish. Natural Language and Linguistic Theory 1: 487-533.

Kayne, Richard S. 1989. Facets of Romance past participle agreement. In Dialect variation and the theory of grammar, ed. Paola Benincà, 85-104. Dordrecht, Holland: Foris Publications.

Noyer, Rolf. 1992. Features, positions and affixes in autonomous morphological structure. Doctoral dissertation, MIT.

Rizzi, Luigi. 1982. Issues in Italian Syntax. Dordrecht: Foris.

Silva-Corvalán, Carmen. 1994. Language contact and change: Spanish in Los Angeles. Oxford and New York: Oxford University Press.

Winford, Donald. 1993. Predication in Caribbean English creoles. Amsterdam: John Benjamins.

Yang, Charles. 2005. On productivity. Linguistic Variation Yearbook 5: 333-370. 